\title{
Effect of Oxygen on the Bonding of Gold to Fused Silica
}

\author{
D. G. Moore and H. R. Thornton
}

\begin{abstract}
Gold pellets were melted on plaques of polished fused silica in vacuum and then heated for 15 minutes at $1,100^{\circ} \mathrm{C}$ under different oxygen pressures. The force required at room temperature to shear the solidified pellets from the silica surface was found to vary from zero for gold melted in vacuum to 725 pounds per square inch for gold melted under an oxygen pressure of 150 millimeters of mercury. In all cases where bond developed, fracture occurred in the silica rather than at the gold-silica interface. Silica plaques with pellets bonded to them by treatment in oxygen showed no measurable strain when examined with a polarograph, suggesting that the gold had yielded as the specimen cooled.

Tests using $\mathrm{Au}^{198}$ as a tracer indicated that gold diffused into the silica lattice at high oxygen pressure but that no diffusion occurred during vacuum heating. Observations made on molten droplets showed no correlation between the contact angles in air and vacuum and the apparent shear strengths. A possible explanation is included to account for this lack of agreement with theory.
\end{abstract}

\section{Introduction}

Recently, while investigating methods of bonding metals to ceramics, it was observed that a very strong bond developed when a small pellet of gold was melted on a fused silica surface in air. Because the gold gave a contact angle of approximately $140^{\circ}$ (no appreciable wetting) and also, because there are no stable oxides reported for gold at its melting tempera.ture, the observed bonding was believed worthy of further investigation.

The present paper summarizes the results of the more extensive study into this unexpected bonding behavior. The effect of oxygen pressure in the furnace atmosphere on bonding was determined; also, numerous observations were made on such effects as gold diffusion into silica, gas evolution, and residual strain. The various observations were then analyzed to determine their possible significance to bonding theory.

Earlier work on bonding in the Enameled Metals Laboratory was supported by the National Advisory Committee for Aeronautics. These earlier studies were mostly concerned with the adherence of vitreous coatings to metals $[1-7] .^{*}$
The present investigation was supported, in part, by the Bureau of Aeronautics, Department of Navy.

\section{Materials}

Three different golds were used in different parts of the program. Golds A and B were of similar purity. The identification of each of the gold samples and the results of their qualitative spectrochemical examination are given in table 1 . No quantitative determinations were made.

The fused silica was procured as transparent optically-polished disks or plaques, $1 / 2$ in. diam by $1 / 8$ in. thick. A qualitative spectrochemical examination of a single disk showed that the principle metallic element impurities were aluminum and titanium which were estimated to be present in the range of 0.01 to 0.1 percent by weight. Other elements detected included silver, calcium, copper and magnesium estimated to be less than 0.001 percent, and manganese estimated to be less than 0.0001 percent.

*Figures in brackets indicate the literature references at the end of this paper.

TABLE 1. Cualitative spectrographic analyses of golds a

\begin{tabular}{|c|c|c|c|c|c|}
\hline \multirow{2}{*}{ Metal } & \multirow{2}{*}{ Deseription } & \multirow{2}{*}{ Source } & \multicolumn{3}{|c|}{ Impurities present in estimated concentration range of } \\
\hline & & & $\begin{array}{l}0.001 \text { to } 0.01 \\
\text { wt } \%\end{array}$ & 0.0001 to $0.001 \mathrm{wt} \%$ & $<.001 \mathrm{wt} \%$ \\
\hline Gold A . & 3-mm-diam high-purity & (b) & None_... & $\mathrm{Ag}, \mathrm{Fe}, \mathrm{Pb}, \mathrm{Si}$ & $\mathrm{Cu}, \mathrm{Ca}, \mathrm{Mg}$ \\
\hline Gold B.. & $\begin{array}{l}\text { Ingot prepared bymelting } \\
\text { purified sponge in }\end{array}$ & (c) & None.. & $\mathrm{Cu}, \mathrm{Ag}, \mathrm{Fe}, \mathrm{Pb}, \mathrm{Si}$ & $\mathrm{Ca}, \mathrm{Mg}$ \\
\hline Gold $\mathrm{C}_{\text {_. }}$. & $\begin{array}{l}\text { graphite. } \\
\text { Metallurgically pure wire }\end{array}$ & (d) & $\mathrm{Ag}, \mathrm{Si}, \mathrm{Pd}$ & $\mathrm{Cu}, \mathrm{Fe}, \mathrm{Mg}, \mathrm{Pb}$ & $\mathrm{Ca}$ \\
\hline
\end{tabular}

a Analyses by Spectrochemistry Section; except for gold, elements other than those listed were not detected.

b Obtained from Jo'nson, Mathey and Co. Ltd., 73/83 Hatton Garden, London, England.

e Prepared at NBS.

d Source unknown. 


\section{Procedures and Results}

\subsection{Shear Strength Measurements}

Gold B was obtained by melting gold sponge in vacuum in a high-purity graphite boat. After cooling, small pieces weighing approximately 0.5 $\mathrm{g}$ each were cut from the ingot with a sharp steel blade. The samples were immersed in warm hydrochloric acid for $15 \mathrm{~min}$ to remove contamination from the cutting operation.

The gold B specimens were next melted on the fused silica plaques in a small Nichrome-wound, Alundum tube furnace. The plaques rested on two sapphire rods which were leveled prior to test.

Two plaques were placed in the hot zone of the furnace for each test. The temperature was measured by means of a noble metal thermocouple, positioned adjacent to the plaques near the center of the furnace. The furnace was mounted in a large bell jar which could be evacuated to a pressure of $10^{-6} \mathrm{~mm}$ of mercury. The specimens were heated to $1,100^{\circ} \mathrm{C}$ in $20 \mathrm{~min}$. During this heating period, the pressure in the bell jar never exceeded $6 \times 10^{-4} \mathrm{~mm}$ of mercury. After $1 \mathrm{~min}$ at $1,100^{\circ} \mathrm{C}$, oxygen that had been passed through a liquid nitrogen cold trap was admitted until the desired pressure had been reached. The temperature was then maintained at $1,100^{\circ} \pm 15^{\circ} \mathrm{C}$ for an additional $15 \mathrm{~min}$ after which the power was turned off and the specimens were allowed to cool with the furnace. The selected oxygen pressure was maintained throughout the $15 \mathrm{~min}$ heating period and also during the cooling. In the tests in which no oxygen was admitted, the pressure in the chamber was maintained at $3 \times 10^{-5} \mathrm{~mm}$ during the $15 \mathrm{~min}$ heating period and also during cooling.

Air rather than oxygen was used for the furnace atmosphere in a few of the early tests. In these tests, the procedures were the same as when the tests were made in oxygen.
All gold pellets adhered to the silica surfaces except those heated in vacuum. Figure 1 shows a gold pellet on a fused silica plaque after the $15 \mathrm{~min}$ treatment at an oxygen pressure of $200 \mathrm{~mm}$ of $\mathrm{Hg}$. Also shown is a similar specimen in which the gold pellet has been sheared from the silica surface. The surface of the silica glass has been shattered and slivers of silica are still adhering to the surface of the gold.

The equipment used for determining the force necessary to shear the gold pellet from the silica surface is shown schematically in figure 2. The silica plaque, with pellet attached, was first seated with a hard grade of plaster of Paris in the lower brass block (A) so that the top surface of the plaque was flush with upper surface of the brass. After the plaster hardened, a grease film was applied to the surface of the plaque, to the exposed surface of hardened plaster, and to the adjacent areas of polished brass. The upper brass block (B) was next centered over the specimen and the intervening space between the gold pellet and the hole in the upper block filled with plaster.

As soon as this second plaster investment hardened, the assembly was placed in position on the base plate (C) and a straight tensile force was applied to the upper brass block at the rate of $535 \mathrm{~g}$ per min. In each case the force required for failure was corrected for static friction. Several tests on a plaque with no gold shows this static friction varied between 85 and $110 \mathrm{~g}$, the average being $98.5 \mathrm{~g}$.

The area of contact between the gold and silica was determined by projecting a magnified image of the interface between the gold and silica on a ground glass screen. Thin paper was placed against the screen and a pencil trace made of the contact area. The paper was next cut along the traced lines and the weight of the cut-out area determined. This weight was then converted to area of contact from the known magnification and the previously determined weight per unit area of the paper.

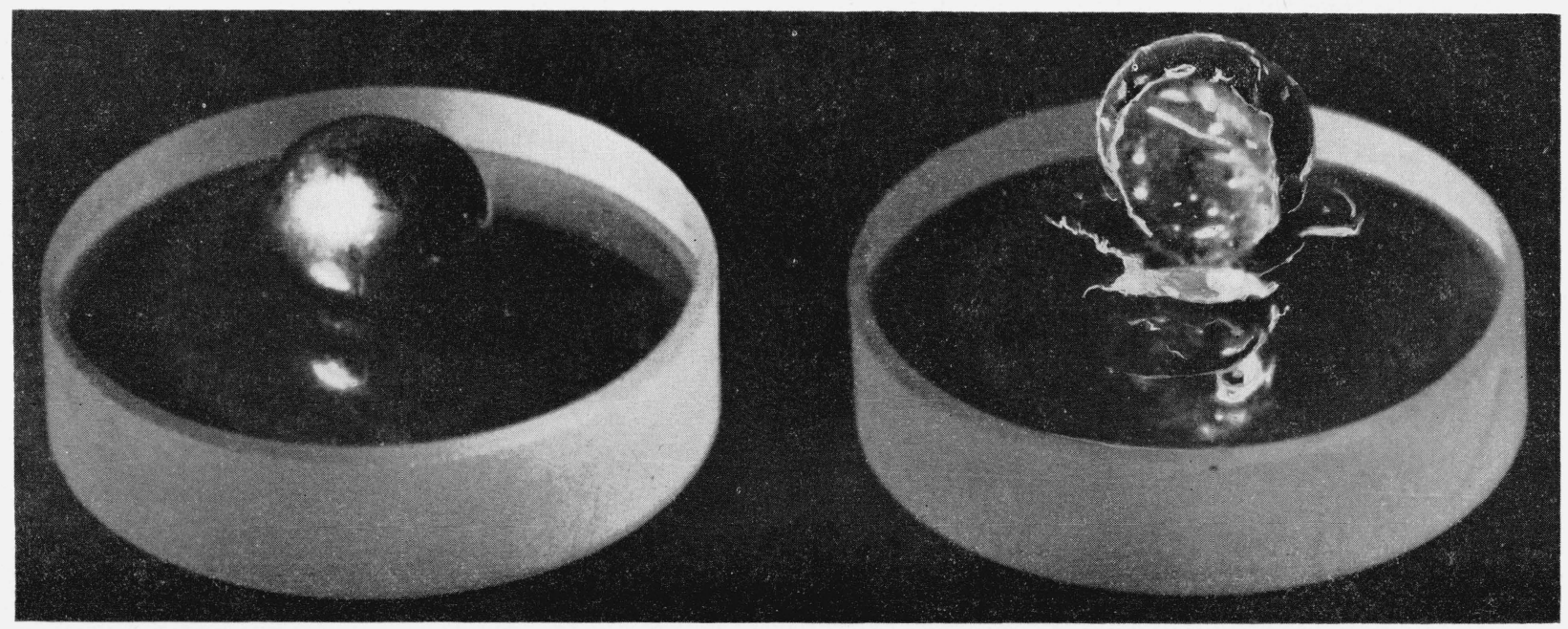

Figure 1. Gold pellets on $1 / 2$ in. diam fused silica plaques after 15 min heating at $1,100^{\circ} \mathrm{C}$ in oxygen at a pressure of $200 \mathrm{~mm}$ of $\mathrm{Hg}$. Fracture occurred in glass rather than at interface when pellet at right was sheared from silica surface. 


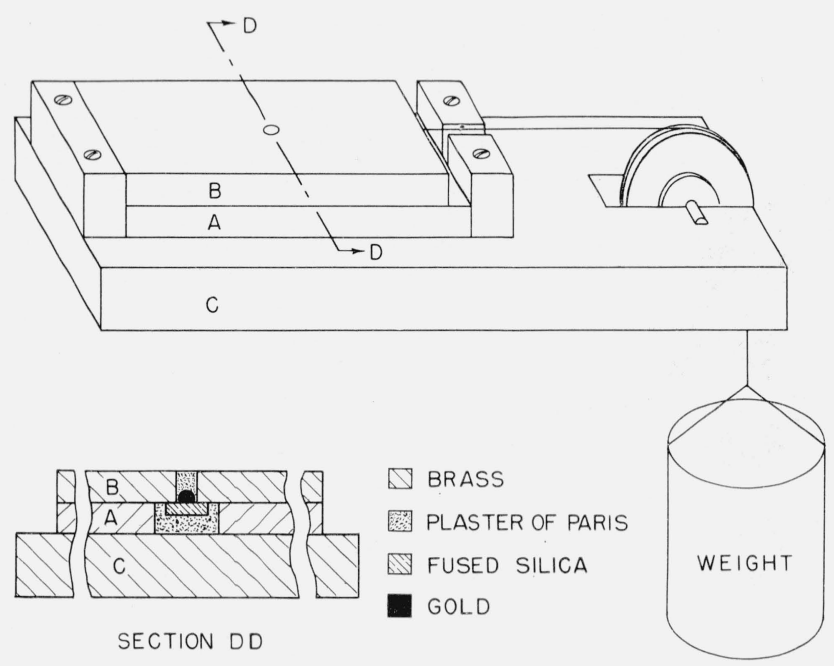

Figure 2. Schematic drawing of shear test apparatus.

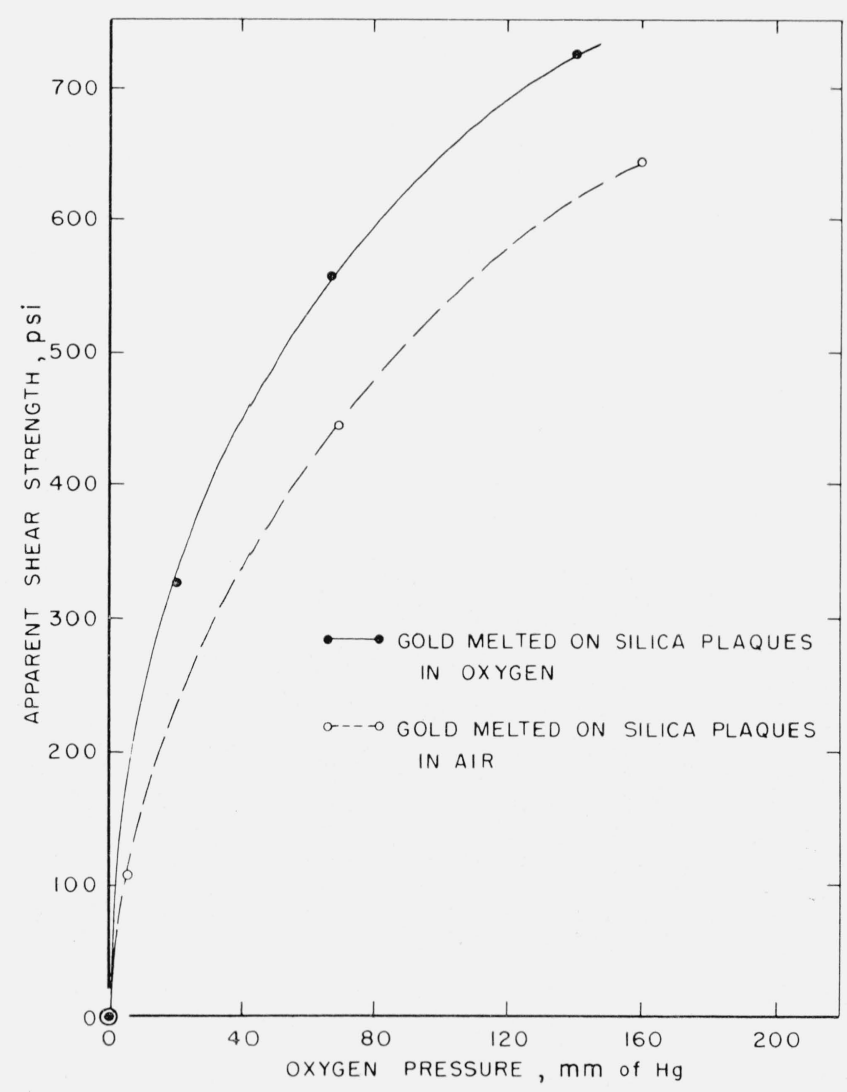

Figure 3. Effect of oxygen pressure in the furnace on the room-temperature shear strength of gold pellets bonded to fused silica by heating $15 \mathrm{~min}$ at $1,100^{\circ} \mathrm{C}$ in air and oxygen.

Shear strengths were obtained by dividing the force to cause fracture by the contact area; the values do not represent true bond strengths.
Figure 3 shows how the apparent shear strength changed with oxygen pressure when pellets of gold $B$ were melted in air and in oxygen. The data used in plotting the two curves are listed in table 2. The value for the apparent shear strength at an oxygen pressure of $500 \mathrm{~mm}$ (spec. 13) is not plotted in figure 3. However, table 3 shows that it is lower than the value at $150 \mathrm{~mm}$ by some 15 percent, thus suggesting that the apparent shear strength may go through a reversal at high oxygen pressures.

TABLE 2. Shear test results for $0.5 \mathrm{~g}$ pellets of gold $B$ on fused silica plaques

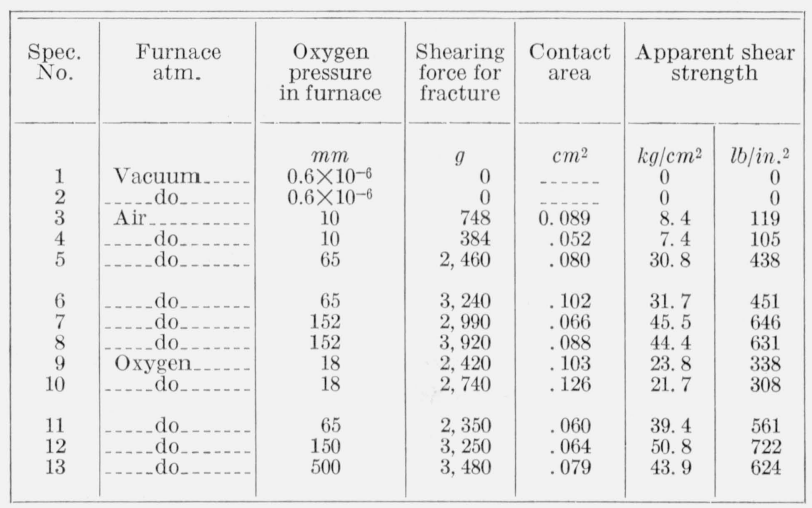

\subsection{Observations of Strain in Fused Silica}

The shear values plotted in figure 3 and listed in table 2 were measured at room temperature. During cooling the gold would contract at a much faster rate than the silica, thus tending to introduce strain into the system. To determine whether such strain was present, several silica disks were examined with a polarograph before pellets of gold A were sheared from the surfaces. The disks were viewed at several orientations, but in no case was any measurable strain detected. This condition could exist only if the gold yielded during the slow cooling in the furnace. Wrought and annealed high-purity gold is reported to have no yield strength $(0.2 \%$ offset $)$ at room temperature [8]; hence, such yielding is not unlikely.

The polarograph showed evidence of very slight strain in the silica for specimens with pellets of gold $\mathrm{B}$ and $\mathrm{C}$, but this strain was too small for measurement with the polarograph.

\subsection{Gas Occlusion at Interface}

All specimens except those tested in vacuum showed gas occlusions present at the interface and, in some cases, the interfacial area taken up by the gas occlusions was as much as 50 percent of the total area of contact. ${ }^{1}$

1 The area of observable voids was subtracted in determining the effective area of contact between gold and silica for computations of the apparent shear strengths. 
An attempt was made to determine the stage in the melting and cooling operations at which the gas occlusions formed. A silica disk with a pellet of gold $\mathrm{C}$ at its midpoint was placed on a hollow refractory pedestal that projected up into the hot zone of a wire-wound tube furnace. A telescope having a magnification of $3 x$ was then focused on the goldsilica contact area by sighting through the clear silica disk. A mirror placed immediately below the pedestal permitted the observations to be made with the telescope in a horizontal position. Differences in emissivity between the clear fused silica, the gold surface, and the gas occlusions gave good contrast at temperatures above about $800^{\circ} \mathrm{C}$ and no outside light source was needed.

The first observations were made in air. It was found that the gas occlusions began forming at the instant of melting and that they continued to grow in size for a period of several seconds. On further heating, the occlusions coalesced into several larger voids which remained substantially unchanged through several cycles of freezing and remelting. In other words, the observations in air were positive in showing that the entrapment of gas occurred only at the time of the first melting.

Similar experiments were made with the furnace placed in a vacuum chamber. The interface was observed through a window sealed into the bottom of the chamber. In these tests, no bubbles were observed on vacuum melting; however, tiny occlusions began to form at the interface shortly after air was admitted to the system and these grew slowly in size with continued heating at $1,100^{\circ} \mathrm{C}$.

\subsection{Etching of Silica by Gold}

Pellets of gold A that had been melted on a silica plaque in vacuum and then heated for $15 \mathrm{~min}$ at $1,100^{\circ} \mathrm{C}$ at an oxygen pressure of $200 \mathrm{~mm}$ of $\mathrm{Hg}$ were dissolved from the silica surface with aqua regia. Examination of the silica surface after this treatment showed a very light etch at the outer edge of the gold-silica contact area. A similar etch also occurred at the outer edge of occluded gas bubbles. The etched surface on one of these fused silica disks was examined with the electron microscope. A replica was first prepared and this replica then shadowed by chromium vapor deposition prior to examination. Figure $4 \mathrm{~A}$ shows the appearance that was typical near the outer edge of the contact area. The depth of these surface depressions is of the order of $30 \mathrm{~m} \mu$. Figure $4 \mathrm{~B}$ shows an area of lesser attack while $4 \mathrm{C}$ is of a peculiar craterlike attack that was observed at one location near the gold-silica-oxygen interface. These craters extended into the silica to a depth of approximately $100 \mathrm{~m} \mu$.

As mentioned earlier, the gold pellets that had been melted and heated on silica plaques in vacuum came free of the silica surface on cooling. None of these plaques showed any evidence of a surface etch. Also, no etch was observed when one of these same plaques was immersed for $17 \mathrm{hr}$ in aqua regia.
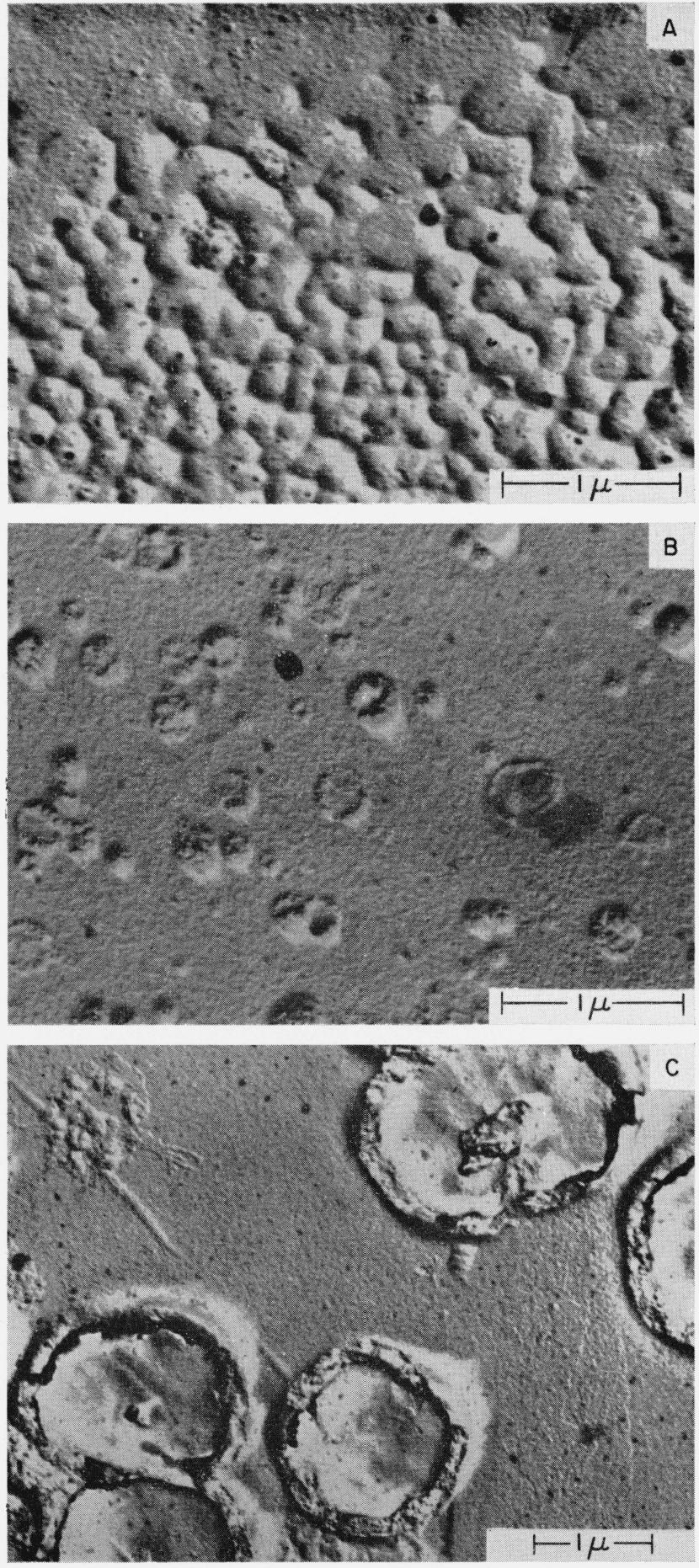

FiguRE 4. Electron micrographs of the surface of fused silica from which the gold pellet had been dissolved with aqua regia.

Specimen had been heated for $15 \mathrm{~min}$ at $1,100^{\circ} \mathrm{C}$ at an oxygen pressure of $200 \mathrm{~mm}$ of $\mathrm{Hg}$. Micrographs are of replicas taken from "outer rim" of contact area.

\subsection{Diffusion of Gold Into Silica}

Two pellets of gold A were irradiated for 1 week in the graphite reactor at the Oak Ridge National 
Laboratories. This treatment transformed some of the $A u^{197}$ to $A u^{198}$. The $A u^{198}$ isotope has beta emissions at $0.28,0.96$, and $1.37 \mathrm{Mev}$ and gamma emissions at $0.41,0.68$, and $1.09 \mathrm{Mev}$. The halflife of the isotope is 2.7 days.

The first of the two pellets was placed on a silica plaque and heated to $1,100^{\circ} \mathrm{C}$ for $15 \mathrm{~min}$ in a vacuum of $3 \times 10^{-5} \mathrm{~mm} \mathrm{Hg}$. On cooling, the pellet was lifted from the plaque and the plaque then immersed in aqua regia for $30 \mathrm{~min}$ to remove any vapor deposited gold from the silica surfaces (v.p. of gold at $1,100^{\circ} \mathrm{C}$ is approximately $10^{-5} \mathrm{~mm}$ of $\mathrm{Hg}$ ). After thorough rinsing in water and drying, the plaque was placed in a lead shield with fixed geometry and a count made on the desired area with a scaler counter using a Geiger-Müller tube with a thin mica window. The count was not significantly above background, thus proving that no measurable diffusion of gold into silica had occurred during the vacuum melting operation. ${ }^{2}$

The second pellet also was melted on a silica plaque in vacuum but immediately after melting, oxygen at $200 \mathrm{~mm}$ pressure was admitted. The specimen was then heated at $1,100^{\circ} \mathrm{C}$ for $15 \mathrm{~min}$ in this atmosphere after which it was allowed to cool with the furnace. The pellet, which was firmly attached after cooling, was then dissolved from the silica plaque by placing the specimen in aqua regia at $24^{\circ} \mathrm{C}$ for $17 \mathrm{hr}$. Examination of the silica surface after removal of the gold showed that a light etching had occurred at the periphery of the contact area and also around occluded gas bubbles. The surface was radioactive. Counts were made on areas between small lead shields placed at selected locations on the plaque surface and these counts demonstrated that the activity was concentrated at the etched areas. This finding was later confirmed by an autoradiograph, an enlargement of which is shown in figure 5.

It is conceivable that the observed confinement of radioactivity to the etched areas could have been caused by gold chloride that had become adsorbed in these areas during the solution treatment in aqua regia. As a check on this possibility, the plaque was subjected to a series of treatments in boiling distilled water. Because gold chloride is soluble in hot water, such a treatment would be expected to remove at least a part of the dissolved salt. Counts were made before and after each treatment and these counts were compared with the normal decay rate of $\mathrm{Au} \mathrm{u}^{198}$ which was computed from the equation:

$$
A=A_{0} e^{-0.693 t / 64.8}
$$

where

$$
\begin{aligned}
A & =\text { activity at time } t \\
A_{0} & =\text { activity at the beginning of the experiment } \\
t & =\text { elasped time in hours. }
\end{aligned}
$$

The data, which are listed in table 3, show that no significant reduction in activity occurred from the boiling water treatments, thus indicating that

\footnotetext{
${ }^{2}$ It is possible that some gold may have been present in the outermost layers of the silica lattice and that this gold was dissolved by the aqua regia treatment. However, it is highly unlikely that gold which had diffused into the silica structure for a discrete distance could be removed by a relatively short treatment in aqua regia at room temperature.
}

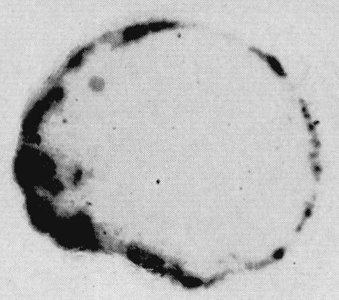

Figure 5. Autoradiograph $(\times 10)$ of a surface of fused silica after removal with aqua regia of gold pellet containing $\mathrm{Au}^{198}$.

Region of $\mathrm{Au}^{198}$ activity corresponds with the outer edge of the contact area between the gold pellet and the silica. Specimen had been heated for $15 \mathrm{~min}$ at an oxygen pressure of $200 \mathrm{~mm}$ of $\mathrm{Hg}$.

TABLE 3. Effect of boiling water treatments on activity of silica plaque on which $\mathrm{Au}^{198}$ had been melted

\begin{tabular}{|c|c|c|c|}
\hline $\begin{array}{c}\text { Time in } \\
\text { boiling } \\
\text { water }\end{array}$ & $\begin{array}{c}\text { Elapsed } \\
\text { time } \\
\text { between } \\
\text { counts }\end{array}$ & $\begin{array}{c}\text { Activity in counts per } \\
\text { min }\end{array}$ \\
& & $\begin{array}{c}\text { Calculated } \\
\text { from decay } \\
\text { rate }\end{array}$ & $\begin{array}{c}\text { Measured } \\
\text { value a }\end{array}$ \\
\cline { 1 - 1 }$h r$ & & & \\
0 & $h r$ & & \\
0.25 & 1.0 & 223 & 218 \\
2.0 & 3.5 & 217 & 215 \\
16.0 & 21.0 & 180 & 182 \\
\hline
\end{tabular}

a Average of five counts.

the activity of the specimen was not caused by adsorbed gold chloride. It will be noted that the observed decay rate follows that for $\mathrm{Au}^{198}$ showing that the activity of the specimen was caused by $A u^{198}$ and not by some trace impurity that was transformed to a radioactive isotope by treatment in the pile.

A second possibility was that the activity resulted from flecks of metallic gold that were not completely removed from the etched area by the $17-\mathrm{hr}$ treatment in aqua regia. If this was the case, then treatment in warm aqua regia should reduce the activity of the specimen by a measurable amount. That such a reduction did in fact occur during the first of three treatments is shown by data listed in table 4 .

These results suggest that a very small amount of gold was present either in the surface depressions or in the top layer of the silica lattice and that this gold was removed by the first half-hour treatment in warm aqua regia. However, the finding that further treatment caused no reduction beyond the normal decay rate, strongly indicated that some of the $\mathrm{Au}^{198}$ had diffused into the silica lattice. The actual amount was small, being of the order of $9 \times 10^{-9} \mathrm{~g}$, or $2.8 \times 10^{13}$ atoms. $^{3}$

${ }^{3}$ Computed from counts made from a gold standard prepared from foil that was irradiated in the same container with the pellets. 
TABLE 4. Effect of warm aqua regia treatments on activity of silica plaque on which $\mathrm{Au}^{198}$ had been melied

\begin{tabular}{|c|c|c|c|c|}
\hline \multicolumn{2}{|c|}{$\begin{array}{l}\text { Treatment in } \\
\text { aqua regia }\end{array}$} & \multirow{2}{*}{$\begin{array}{l}\text { Elapsed } \\
\text { time } \\
\text { between } \\
\text { counts }\end{array}$} & \multicolumn{2}{|c|}{$\begin{array}{l}\text { Activity in counts } \\
\text { per min }\end{array}$} \\
\hline Time & Temp. & & $\begin{array}{l}\text { Calcu- } \\
\text { lated } \\
\text { from } \\
\text { decay } \\
\text { rate }\end{array}$ & $\begin{array}{l}\text { Meas- } \\
\text { ured } \\
\text { value a }\end{array}$ \\
\hline $\begin{array}{l}\min \\
30 \\
30 \\
30\end{array}$ & $\begin{array}{c}{ }^{\circ} C \\
-38 \\
38 \\
70\end{array}$ & $\begin{array}{l}h r \\
0 \\
3 \\
41 / 4 \\
61 / 4\end{array}$ & $\begin{array}{r}101 \\
99 \\
94\end{array}$ & $\begin{array}{r}108 \\
93 \\
92 \\
86\end{array}$ \\
\hline
\end{tabular}

a Average of five counts.

\subsection{Region of Maximum Bonding}

Two experiments were performed in an attempt to determine if the observed bonding was concentrated in that region of the contact area where etching and gold diffusion had occurred; i.e., at the outer rim.

In the first experiment, silica plaques having different sized pellets of gold A positioned at their midpoint were prepared and treated for $15 \mathrm{~min}$ at $1,100^{\circ}$ at an oxygen pressure of $10 \mathrm{~mm}$ of $\mathrm{Hg}$. After cooling, the apparent shear strengths were measured. The results are listed in table 5. The trend of higher shear strengths with decreasing peliet size suggests that the bond was not uniform over the entire contact area, but rather that it was stronger along the outer rim.

TABLE 5. Effect of size of gold pellet on apparent shear strength

\begin{tabular}{|c|c|c|c|}
\hline $\begin{array}{c}\text { Weight of } \\
\text { gold pellet }\end{array}$ & $\begin{array}{c}\text { Au-SiO } \\
\text { contact } \\
\text { area }\end{array}$ & \multicolumn{2}{|c|}{$\begin{array}{c}\text { Apparent shear } \\
\text { stength }\end{array}$} \\
\cline { 1 - 2 }$g$ & $\begin{array}{c}\mathrm{cm}^{2} \\
g\end{array}$ & $g / \mathrm{cm}^{2}$ & $\mathrm{lb/in.} .^{2}$ \\
0.129 & 0.0205 & 61,450 & 870 \\
.556 & .0565 & 56,900 & 810 \\
.876 & .0606 & 42,800 & 610 \\
\hline
\end{tabular}

In the second experiment, four pellets of gold A, each weighing about $0.8 \mathrm{~g}$, were placed on silica plaques and treated for $15 \mathrm{~min}$ at $1,100^{\circ} \mathrm{C}$ at an oxygen pressure of $100 \mathrm{~mm}$ of $\mathrm{Hg}$. On cooling, the silica plaques were encased in a short section of brass tubing with plaster of Paris; the pellet in each case projected from the end of tube and was free of the plaster. The encased plaque was then placed in a lathe and the gold pellet machined down to about three-fourths of its original diameter. Individual cuts were of the order of 0.0005 to 0.001 in. During each pass, the lathe tool closely approached, but did not touch, the silica surface. The goal of the experiment was to compare the shear test values of normally prepared specimens with the values obtained on specimens from which the "outer rim" of gold had been removed.

The machining operation was attempted on all four specimens. In three of the specimens the gold came free of the silica before the diameter was reduced by the desired amount. Examination showed little or no fracture in the silica glass such as was invariably observed whenever oxygen-treated specimens with the "outer rim" intact were sheared from the silica surface (see fig. 1B). The machining of the fourth specimen was completed without separation of the gold pellet. However, the bonding was so weak with the "outer rim" removed that the pellet parted from the plaque when an attempt was made to mount the specimen in the brass block for the shear test determination. Examination showed no fracture in the silica surface.

Thus, although neither of the two experiments gave quantitative results, both indicated that the bonding was greater at the outer edge of the contact area than it was in the interior.

\subsection{Contact Angle}

A Leitz high-temperature microscope was used to observe and photograph molten drops of gold $\mathrm{A}(0.5 \mathrm{~g})$ resting on polished plaques of fused silica. The furnace was platinum-wound and could be operated in either air or vacuum. The drop was observed through a Vycor window sealed into the furnace shell.

Figure $6 \mathrm{~A}$ is a photograph of a molten drop of gold $\mathrm{A}$ in vacuum $\left(1 \times 10^{-3} \mathrm{~mm}\right.$ of $\left.\mathrm{Hg}\right)$ at $1,100^{\circ} \mathrm{C}$. Figure $6 \mathrm{~B}$ shows the same drop $5 \mathrm{~min}$ after air had been admitted to the system. Contact angles were measured on enlarged prints using a precision protractor. The angle in vacuum (fig. 6A) was $138^{\circ}$; the angle in air (fig. 6B) was $136^{\circ}$.

\section{Discussion of Results}

Release of strain by yielding of the gold during cooling permitted the apparent shear strengths to be measured at room temperature. Without this yielding excessive stresses would have been generated. during cooling because of the large differences in thermal expansion coefficient (gold $16.9 \times 10^{-6}$ per ${ }^{\circ} \mathrm{C}$ from $20^{\circ}$ to $1,000^{\circ} \mathrm{C}$; fused silica about $0.6 \times 10^{-6}$ over the same range). The polarograph was positive in showing that no strain was present for gold $\mathrm{A}$ on silica and no measurable strain for golds B and C. Even with no measurable strain, however, the shear test measurements did not give true bond strengths because of fracture in the silica glass. Also, if the bond is concentrated at the outer-rim of the contact area, as the experiments described in section 3.6 indicate, the shearing stress to cause failure of the bond would be much greater than the values listed. in table 2 . 

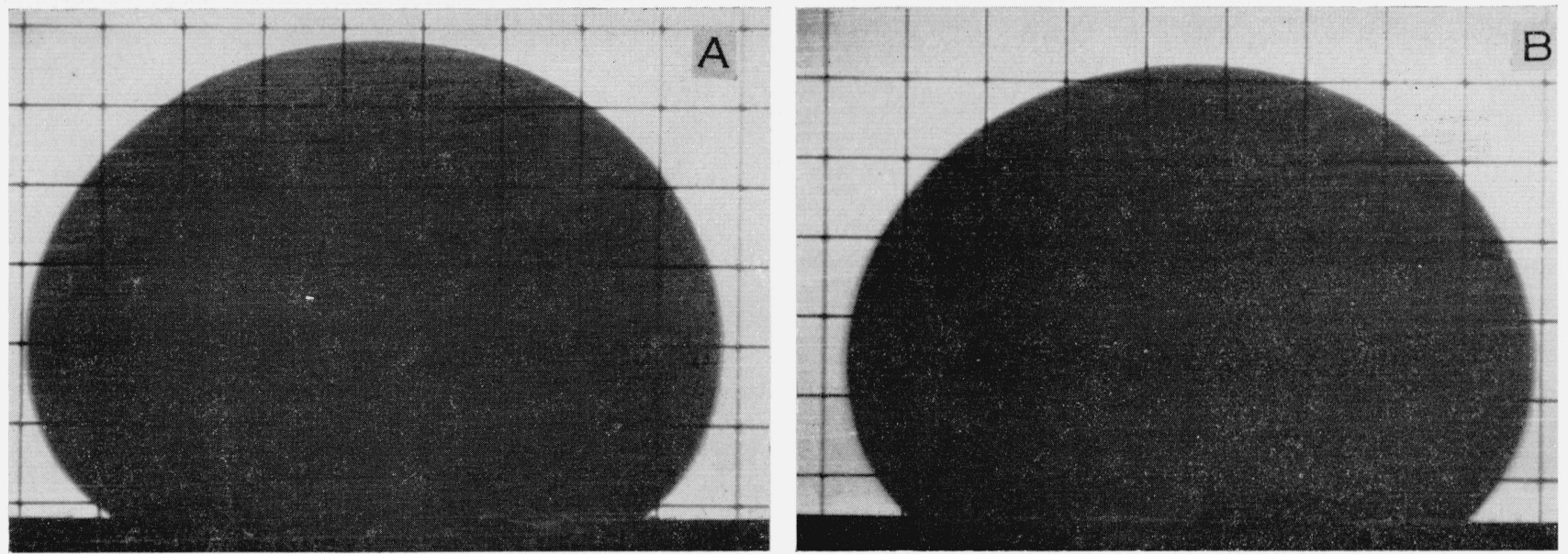

Figure 6. Sessile drops of gold $A$ on a silica plaque.

$A$, In vacuum at $1,100^{\circ} \mathrm{C} ; \mathrm{B}$, in air at $1,100^{\circ} \mathrm{C}$. Sides of grid squares are $0.5 \mathrm{~mm}$.

Impurities present in the fused silica undoubtedly had some influence on bond development but it is doubtful that the impurities exerted a controlling influence. A few tests made early in the study with high purity disks of polished sapphire gave the same type of results as were obtained with silica; the gold pellet developed no bond in vacuum yet in air the bond was so strong that fracture of the crystal occurred when the cooled pellet was pried loose from the sapphire surface. Baes and Kellogg [9] noted a similar behavior when working with sessile drops of copper that were cooled in contact with fused silica. In this system the presence of only a trace of oxygen permitted a strong bond to develop; fracture of the silica was observed when the pellet was pried from the surface.

Gas occlusions at the interface were noted for the specimens of gold melted on sapphire in air, as well as for specimens of gold on silica; gas occlusions were also noted by Baes and Kellogg [9] in the coppersilica system. The composition of the gas in the occlusions was not determined but is probably oxygen. According to Smithells [10], oxygen is strongly adsorbed by gold at room temperature. It may be that this adsorbed gas is released on melting and becomes trapped at the interface. Such a hypothesis, however, fails to explain why gold melted on silica in vacuum gradually accumulates occluded bubbles when air or oxygen is later admitted to the system.

Figure 4 shows that the silica surface in contact with the molten gold became slightly pitted during heating in oxygen. In the case of porcelain enamels on steel, Richmond et al. [2] showed that a correlation existed between roughness of interface and adherence. The etching of the steel occurred during the firing treatment. "Anchor points" were de. tected at the interface which could conceivably have caused a mechanical anchoring of the enamel layer. Later work by Moore and Eubanks [7] showed, however, that excellent bonding was possible without detectable interface roughening when similar enamels were applied to stainless steel. The pitting of the silica as observed in the present study was of a very small magnitude as is shown in figure 4 . It seems highly unlikely that roughness on this scale could provide any appreciable mechanical interlock between the gold and silica.

All of the known oxides of gold decompose to the metal when heated at temperatures above $250^{\circ} \mathrm{C}$. Recently, however, Carpenter and Maier [11] noted that oxygen was consumed when gold filaments were heated to about $900^{\circ} \mathrm{C}$ at oxygen pressures in the range 1 to $10 \mu$. Their tentative explanation for the loss of oxygen was that a volatile gold oxide formed and deposited on the walls of the chamber. Finch and coworkers [12] observed extra rings in electron diffraction studies when gold foil was heated to $300^{\circ} \mathrm{C}$ in air. These rings, which corresponded to a close-packed hexagonal structure, disappeared when the foil was reheated in vacuum. They concluded that the oxygen entered the gold lattice, forming a solid solution within the surface layers.

Thus, there is some evidence for a gold-oxygen interaction at high temperatures and, in fact, such a reaction appears to be necessary to explain the strong bonds that were observed when oxygen was present. One possible explanation for bond formation in the presence of oxygen is as follows; (a) a relatively small amount of gold oxide forms by oxidation when the gold is heated to $1,100^{\circ} \mathrm{C}$ in the presence of oxygen, (b) some of the oxide that forms at the edge of the contact area between the gold droplet and the silica diffuses in to the glass structure, and (c) a strong bond developes between the droplet and the gold-enriched layer of silica.

The formation of bond when the oxide of the substrate metal diffuses into a glass is in keeping with the results of a recent investigation by King and coworkers [13]. These investigators reported that strong "chemical bonds" developed only when a glass was "saturated" with the ion of the metal with which the glass was in contact. Such a requirement presupposes that there is a strong bond linkage between the atoms of the substrate metal and the ions of the same metal in the glass. Before accepting this hypothesis, it would need to be shown conclusively that an affinity of this kind actually exists. 
In the foregoing it has been assumed that gold atoms could not enter the silica lattice structure and that for such diffusion to occur the gold would need to oxidize and enter the lattice as gold oxide. The observation that diffusion occurs only when oxygen is present supports this contention. Weyl [14], on the other hand, cites numerous examples from the German literature in support of small amounts of metal being soluble in glasses and molten salts. If such solubility can occur, and if metal solubility in the glass is enhanced by the presence of ions of the same metal, as implied by Weyl [14], then it is conceivable that a strong linkage might develop between the metal atoms dissolved in the outermost lavers of the glass and the metal atoms in the substrate.

\section{Comments on Lack of Correlation Be- tween Contact Angle and Bond Strength}

The observation that wide variations in bond occurred without any appreciable change in contact angle is contrary to what might be expected from surface energy relationships. For example, the work of adhesion, which is defined as the work required to separate a liquid from a solid, is given by the following expression :

$$
W_{\mathrm{adh}}=E(1+\cos \theta)
$$

$E=$ surface energy between liquid and its vapor

$\theta=$ contact angle between liquid and solid when measured through the liquid.

When $\theta=0$ the liquid completely wets the solid and the work of adhesion is equal to twice the surface tension of the liquid. Because the degree of bonding should be related to work of adhesion, many investigators associate good bonding in a stress-free system with low contact angles and poor bond with high angles. The observations with the polarograph showed little or no stress in the system; hence, from eq (2), almost equal works of adhesion (similar bond strengths) would be predicted for the specimens heated in air $\left(\theta=136^{\circ}\right)$ and in vacuum $\left(\theta=138^{\circ}\right)$. The finding that the strength of the bond was different by many orders of magnitude suggests that either (1) the contact angle observed in air is not a true equilibrium angle, or (2) the energy relationships of eq (2) do not apply to this system.

Concerning the first possibility, it seemed conceivable that the contact angle observed in air might be dependent on the extent to which gold had diffused laterally along the silica surface. To test this possibility, an experiment was performed in which a pellet of gold $\mathrm{A}$ was first melted on a silica plaque in air. On cooling, the upper portion of the pellet was removed by hand filing, giving the shape shown in figure 7B. This was done carefully so as not to disturb the bond to the silica surface. The specimen was then remelted in air. Figure $7 \mathrm{C}$ shows that the new molten droplet did not pull away from the original line of contact but rather assumed a new
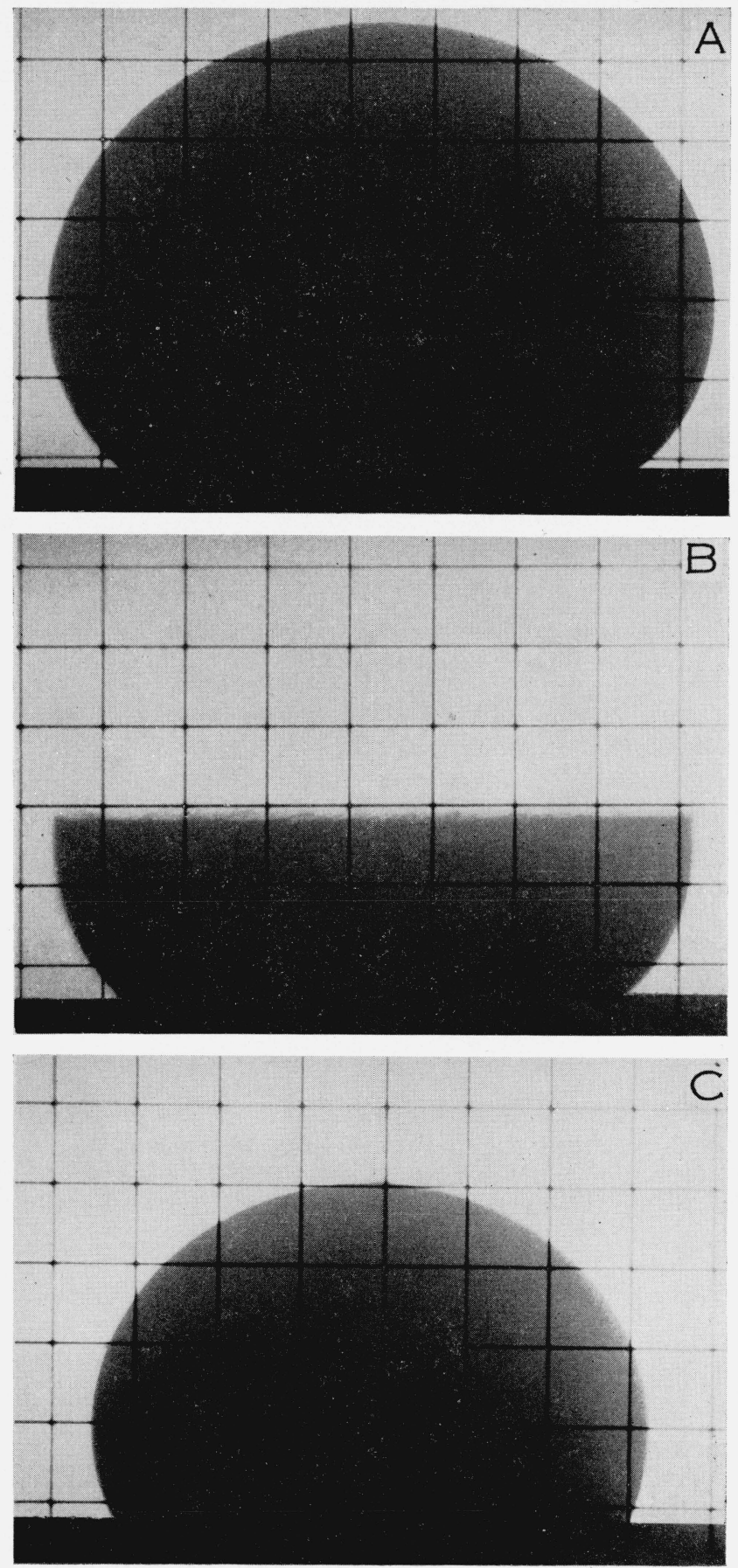

Figure 7. Sessile drops of gold $A$ on silica plaque.

$\mathrm{A}$, In air at $1,100^{\circ} \mathrm{C} ; \mathrm{B}$, same drop at $20^{\circ} \mathrm{C}$ after removal of top portion by hand filing; and $\mathrm{C}$, same pellet as $\mathrm{B}$ at $1,100^{\circ} \mathrm{C}$ in air. Sides of grid squares are $0.5 \mathrm{~mm}$.

shape with a smaller contact angle. This behavior at least suggests that once diffusion of gold ions has occurred the molten gold will then wet the silica. It also suggests that the contact angle observed during heating in air is not an equilibrium angle but rather might be expected to change with time as 
gold oxide diffused laterally along the surface of the silica. ${ }^{3}$ Testing of this hypothesis by long-time heating, however, was impossible because prolonged heating at $1,100^{\circ} \mathrm{C}$ causes the silica glass to devitrify.

The second possibility, namely that the energy relations of eq 2 do not apply to this or to any real system, is not without some merit. Tabor [15] has pointed out two fundamental defects in the thermodynamic approach. The first is that the thermodynamic quantities connected with the work of adhesion are concerned with the energy change occurring when the liquid is placed on or removed from the surface. These quantities, however, tell nothing about the force with which the adsorbed film will resist shear in a direction tangential to the surface. The second is that in the formation of two new surfaces by rupture, by far the greater part of the energy in most real systems is dissipated in deforming either or both solids and the surface energy is only a small part of the whole energy involved. Yet a third factor is the large influence of stress concentrations along the periphery of the contact area between the adhesive and adherend. These stress concentrations appear whenever a shearing force is applied to a joint and their presence may completely mask any relationship between contact angle and work of adhesion. A discussion of the effects of stress concentrations has been given by de Bruyne [16].

In view of the foregoing considerations, the lack of correlation between work of adhesion and bond strength in the present experiment is not surprising. In fact, it seems unlikely that a correlation of this type would be observable in any real system.

The authors are indebted to Warren D. Hayes who photographed the droplets of molten gold also to W. N. Harrison, Chief of the Enameled Metals Section, for his many helpful suggestions.

\footnotetext{
${ }^{3}$ It is of course possible that the $22^{\circ}$ decrease in contact angle as illustrated in figure $7\left(\theta=137^{\circ}\right.$ in $\mathrm{A}$ and $115^{\circ}$ in $\left.\mathrm{C}\right)$ might be ascribed to the difference in angle that is sometimes observed when a liquid is (a) advancing or (b) receding over the surfores of a rece area might logically be expected for the different sized drops (fig. 7A and 7C) but such a change was not observed.
}

\section{References}

[1] W. N. Harrison, J. C. Richmond, J. W. Pitts, and S. G. Brenner, Migration of cobalt during firing of ground coat enamels, NACA Tech. Note 2695 (1952); also, J. Am. Ceram. Soc. 35, 305 (1953).

[2] J. C. Richmond, D. G. Moore, H. B. Kirkpatrick, and W. N. Harrison, Relation between roughness of interface and adherence of porcelain enamel to steel, NACA Tech. Note 2934 (1953); also, J. Am. Ceram. Soc. 36, 410 (1953).

[3] D. G. Moore, J. W. Pitts, J. C. Richmond, and W. N. Harrison, The galvanic corrosion theory for adherence of porcelain enamel to steel, NACA Tech. Note 2935 (1953); also, J. Am. Ceram. Soc. 37, 1 (1954).

[4] D. G. Moore, J. W. Pitts, and W. N. Harrison, Role of nickel dip in enameling of sheet steel, NACA Tech. Note 3207 (1954); also, J. Am. Ceram. Soc. 37, 363 (1954).

[5] A. G. Eubanks and D. G. Moore, Effect of oxygen con tent of furance atmosphere on adherence of vitreous coatings to iron, NACA Tech. Note 3297 (1955); also J. Am. Ceram. Soc. 38, 226 (1955).

[6] J. C. Richmond, H. B. Kirkpatrick, and W. N. Harrison, The nickel dip: a radioisotope study of metallic deposits in porcelain enameling, NACA Tech. Note 3577 (1956); also, J. Am. Ceram. Soc. 39, 39 (1956).

[7] D. G. Moore and A. G. Eubanks, Influence of copper ions on adherence of vitreous coatings to stainless steel, NACA Tech. Note 3679 (1956); also, J. Am. Ceram. Soc. 39, 357 (1956).

[8] Metals Handbook, p. 1117 (Am. Soc. Metals, Cleveland 3, Ohio, 1948).

[9] C. F. Baes, Jr. and H. H. Kellogg, Effect of dissolved sulphur on the surface tension of liquid copper, J. Metals 5, 643 (1953).

[10] C. J. Smithells, Gases and Metals, p. 67 (Chapman and Hall, Ltd., London, England, 1938).

[11] L. G. Carpenter and W. N. Mair, Reaction between oxygen and hot gold, Nature 179, 212 (1957).

[12] G. I. Finch, A. G. Quarrell, and H. Wilman. Electron diffration and surface structure. Trans. Faraday Soc. 31, 1075 (1935).

[13] B. W. King, H. P. Tripp, and W. H. Duckworth, The nature of adherence of porcelain enamels to metals. (Presented at 58th Annual Meeting of Am. Ceram. Soc., New York City, 1956).

[14] W. A. Weyl, Colored glasses, 333-339 (Publ. by Soc. of Glass Tech., Northumberland Road, Sheffield 10, England, 1951).

[15] D. Tabor, Basic principles of adhesion, Repts. Progr. Appl. Chem. 36, 621 (1951).

[16] N. A. de Bruyne, Fundamentals of adhesion, Research 6, 362 (1953).

Washington, November 20, 1958 


Beginning in July 1959, the Journal of Research will be published in four
separate sections which may be subscribed for individually. This change is being
made to provide a publication whose subject matter concentrates on particular
fields of interest, thus meeting the specialized needs of individual scientists, engi-
neers, and mathematicians.
Section A. Physics and Chemistry, to be issued bimonthly, will present
papers of interest primarily to scientists working in these fields. This section will
cover a broad range of physical and chemical research, with major emphasis on
standards of physical measurement, fundamental constants, and properties of
matter.
Section B. Mathematics and Mathematical Physics, to be issued quar-
terly, will present results in pure and applied mathematics, including mathematical
statistics, theory of experiment design, numerical analysis, and short numerical
tables; theoretical physics, chemistry, and engineering, where the emphasis is on
the mathematical content or methodology; and logical design, programing, and
applications of electronic computers and computer systems.
Section C. Engineering and Instrumentation, to be issued quarterly,
Superintendent of Documents when advance orders for the new sections can be
accepted.
will report results of interest chiefly to the engineer or applied scientist. This sec-
tion will include many of the new developments in instrumentation resulting from
the Bureau's work in physical measurement, data processing, and the development
of test methods. It will also cover some of the work in acoustics, applied me-
chanics, building research, and cryogenic engineering.
Section D. Radio Propagation, to be issued bimonthly, will report research
in radio propagation, communications, and upper atmospheric physics. Topics to
be covered include propagation in ionized media, scattering by turbulence, the
effect of irregular terrain on propagation, diffraction and scattering by solid
obstacles, propagation through time-varying media, and antennas.
ing

